JOURNAL OF ENGLISH STUDIES, I (1999), 29-43

\title{
WHAT'S IN A TITLE? THE STRATEGIC USE OF METAPHOR AND METONYMY IN SOME LIKE IT HOT
}

\author{
Mª DEL ROSARIO CABALLERO RODRÍGUEZ \\ University Jaume I (Castellón)
}

\begin{abstract}
The aim of this paper is to call attention upon the strategic and relevant use of the polysemous nature of language as it is instantiated in film titles such as the one in our discussion. The theoretical framework adopted in our analysis of the concept hot in our title is that of Cognitive Linguistics (Lakoff 1987; Langacker 1987), which explains polysemy in terms of conceptual organisation and categorisation. We defend that the cognitive approach to lexis as an array of semantic networks triggered by the words within them proves a useful explanation in solving a number of troublesome issues in the analysis of short texts like titles, namely the use of implicatures, polysemy, and the ambiguity usually resulting from both.
\end{abstract}

\section{INTRODUCTION}

Titles and headings are usually clear instantiations of the Principle of Relevance ${ }^{2}$ at work: they are extremely economical and, at the same time, need to produce a great contextual effect if they want to be really communicative and fulfil the twofold rhetorical principle underlying them: arousing the interest of an audience towards the product they label, and providing as much information about it as possible in a minimum space. In this sense, titles act as discourse topics of the first order "whose role is precisely to give access to encyclopaedic information crucial to the comprehension of the accompanying

1. Financial support for this research has been provided by the DEGS, grant $n^{\circ}$ PB97-1502.

2. Sperber and Wilson (1986). 
texts" (Sperber \& Wilson 1986: 216), and have, subsequently, been regarded by several researchers as examples of superordinate topics: "cognitive schemata ... [that] could be the topic of the whole text" (Downing \& Locke 1992: 224).

Also, despite their small size, titles partake of the same general characteristics as longer discourse samples: a) they are rhetorically determined by the participants in the communicative event in which they are inserted -the addresser's goals, the addressee's expectations, the context of interaction, and the characteristics of what is being communicated itself; b) they embody an essentially inferential activity that makes use of a number of discursive strategies and procedures in order to convey meaning.

The present paper is concerned with an example of such small pieces of discourse, namely the title of Billy Wilder's film Some Like It Hot, at first sight a rather vague title which, nevertheless, fulfils Sperber and Wilson's Principle of Relevance as we will attempt to demonstrate. In order to do so, we propose an analysis of the title that takes insights from both Discourse Analysis and, above all, Cognitive Linguistics, the latter being an approach which may be useful in order to solve some of the issues which prove more troublesome for the former, namely those of polysemy and the ambiguity usually resulting from it, and the risky nature of implicatures as discourse strategies (all of which are, more often than not, strongly related).

Thus, after briefly introducing the film, we will first consider the kind of strategies used in its title, and the theoretical implications deriving from that use. We will attempt a definition of the concept [HOT] following the frameworks outlined by Langacker (1987) and Lakoff (1987) within the cognitive paradigm. Finally, we will draw some conclusions in the manner of considering the full compatibility of the cognitive rendering of the concept of polysemy and those principles governing discourse and communication, mostly the Principle of Relevance.

\section{Polysemy and Ambiguity in Some Like It Hot: TheORETICAL PREREQUisites}

Billy Wilder's film tells the story of two minor jazz musicians -Joe and Jerryworking in a Chicago speakeasy who, after witnessing the slaughtering of one Mafia gang by another, manage to escape and, in order to avoid being discovered and killed as well, dress as women and join a female music band travelling to Florida. Their new 'feminine' condition is the origin of many comical situations and gags in a film that has become a canonical example of the play around gender issues, equivocation, and transvestism. Thus, Joe and Jerry -transformed into Josephine and Geraldine overnightare not only surrounded by women but also, and most importantly, share their most 
intimate moments and thoughts. Also, both end up competing to gain the favours of a shapely blonde -performed by Marilyn Monroe- who is finally conquered by one of them by means of a complex hide-and-seek game while, at the same time, the other guy becomes engaged to an old millionaire who truly believes he is a lady. Things get complicated after the arrival at their Florida hotel of the Chicago gang from which they are escaping which, after recognising them as the unwanted witnesses of the Chicago slaughter, engage in a hot pursuit that, nevertheless, resolves well at the end.

The film (whose title is in fact intertextually linked to a well-known nursery rhyme ${ }^{3}$ ) works upon a number of commonplaces and issues -girls in search of old millionaires in sunny summer resorts, the world of Mafia gangs and their alcohol business, the laundering of the hot profits resulting from the sale of alcohol and the running of speakeasies (disguised clubs where jazz, girls, and alcoholic drinks were easily available and controlled by the different gangs) in warm and sunny Florida- all of which are linguistically reflected in the many idiomatic expressions containing the word hot, word that encapsulates perfectly the world of danger, sex, and money around which the film pivots.

The word hot is also present in the film's title which, in this case, works upon the general discourse strategy of using a signal that is overtly poor in explicit assumptions leaving therefore a lot to inferencing ${ }^{4}$-a risky strategy inasmuch it engages the audience in a processing effort which is at odds with the Co-operative Principle ${ }^{5}$ in general and the Principle of Relevance in particular underlying the overall communicative purpose of any text. The origin of the title's ambiguity is twofold: first, we have the void pronoun it for which there is no obvious referent, therefore making us face a communicative problem: What is it that is liked hot? Why hot? The second source of ambiguity is the polysemous nature of the adjective hot itself: Which of the many senses of hot is encapsulated in the title? All these questions meet an answer after watching the film, context proving thus to be the main source of disambiguation as many pragmatic and discursive approaches claim.

One way of enriching the approaches mentioned above is to regard the title from a cognitive point of view, concretely from the theory about figurative language and

3. Peas pudding hot

Peas pudding cold

Peas pudding in the pot nine days old

Some like it hot

Some like it cold

Some like it in the pot nine days old

4. For more information about discourse strategies see Otal and Ruiz de Mendoza (1997).

5. Grice (1975). 
thought outlined by Johnson (1987), Lakoff (1987), and Langacker (1987) among others and referred to as experiential realism.

The key notion in the cognitive framework known as experientialism is that thought fundamentally grows out of embodiment, a fact that is evident in the use we make of bodily-grounded preconceptual structures such as Johnson and Lakoff's basic image schemas (up-down, in-out, path schemas) and other basic structures like Langacker's domains to further construct more complex structures which enable us to understand our world. Thus, as Navarro (1998: 68) points out "basic image schemas provide the preconceptual blocks for meaning" which are "combined into conceptual schemas in Langacker's sense" that are the basic structures for more complex mental processes -such as categorisation, schematisation ${ }^{6}$, or metaphoric and metonymic mappings- lying at the basis of our construal of meaning. One of the key issues within the cognitive paradigm is the polysemous nature of most units of language (as it is exemplified by the title under discussion), polysemy which is explained in terms of conceptual organisation and categorisation.

Most linguistic approaches have regarded polysemy (a phenomenon related to a single word having more than one meaning) and the ambiguity usually resulting from it as problematic, mostly due to the high value placed upon the literal meaning of words and expressions. They have usually claimed for the necessity of appealing to the context of the utterance as the only way to capture the sense of the polysemous 'culprit' as it is instantiated each time (each instantiation implying one sense and one dictionary entry so to speak). The phenomenon is usually regarded as the arbitrary result of capricious collocations whereby a word means according to the word immediately before or after it (e.g. 'warm' in 'a warm room' means something different from 'warm' in 'a warm smile'), each collocation implying a different meaning.

On the contrary, cognitive semantics regards polysemy as involving family resemblances, stressing the systematic relationship between the different senses/meanings of a word and including polysemy within an issue of conceptual organisation such as categorisation. Thus, as Lakoff (1987: 334-378) remarks “polysemy involves cognitive categorization in a lexicon. (...) Polysemy appears to be a special case of prototype-based categorization, where the senses of the word are the members of a category."

6. The key role of mental schemas in organising knowledge and comprehension draws upon earlier research in Gestalt psychology and what is known as Schemata Theory in Artificial Intelligence research in the 1970s. In the later 1970s the theory was applied to story comprehension. See Bartlett (1932), Minsky (1975), Winograd (1975), Schank and Abelson (1977), Mandler and Johnson (1977), and Rumelhart (1980). 
A cognitive approach in lexical semantics works against the arbitrary nature of polysemy as the result of collocation. It defends that usage sanctions a word, but this usage is at the same time determined or motivated by cognitive processes and physical experience: "polysemy arises from the fact that there are systematic relationships between different cognitive models and between elements of the same model. The same word is often used for elements that stand in such cognitive relations to one another" (Lakoff 1987: 13).

What this view suggests then is that the meanings of many polysemous words can be explained in terms of basic metaphors and other instances of figurative language that motivate the mapping from a source domain to a target domain, advocating for an encyclopaedic -and holistic- view of meaning: in a sense, each instantiation of a word always retains its whole range of senses regardless of the context in which it appears, senses which are related to one another by various means (determined by cognitive processes such as metaphor). Thus, we could say that a given word belongs to a complex semantic network determined by different domains and cognitive processes, where there may be senses more representative than others. At the same time, all the senses within the category can take us to other relational networks in a similar fashion as that of hypertext ${ }^{7}$ : as Langacker (1987) points out, linguistic expressions are not containers for meaning but, rather, points of access to a network of relations which ultimately defines their semantic value.

We will see how this mechanism works with regard to the word hot in the title under discussion.

\section{TOWARDS A DEFINITION OF THE CONCEPT HOT}

The first step in our analysis is to define the matrix -the cognitive domain(s)- that characterises the predicate of the concept hot. In order to do so, we will combine concepts of two sorts: image-schemas as proposed by Johnson (1987) and the concept of domain within the cognitive framework outlined by Langacker (1987).

According to Langacker (1987), domains are cognitive entities -mental experiences, representational spaces, concepts, or conceptual complexes- that provide the necessary context for the characterisation of a semantic unit. Domains are then classified with regard to three properties (their availability to be reduced to more fundamental

7. The concept of hypertext is currently being applied in lexical semantics. See García, Ruiz de Mendoza, and Otal (1994-95). 
conceptual structures, their dimensionality, and their ability to specify locations or configurations), and thus we have basic domains -primitive representational fields such as smell or touch-giving rise to abstract domains that are "any concept or conceptual complex that functions as a domain for the definition of a higher-order concept" (Langacker 1987: 150) like the human body or a kinship network which, in this sense, correspond roughly to Lakoff's (1987) Idealized Cognitive Models. Both basic and abstract domains can be further described with regard to the number of dimensions accounting for their intrinsic organisation, that is the ordering and distance of the concepts within a domain, and their bounded/unbounded condition with respect to a given dimension. Finally, domains can be locational or configurational depending on whether they presuppose a specific position or value within the system or, rather, there is no such specification.

The concept hot is primarily determined by the human sensory capacity of touch and is characterised by the one-dimensional domain of temperature, a scalar domain which in Langacker's terms is bounded -we are capable of perceiving only a specific range of temperatures at a time- and locational.

Defining hot is, then, a question of designating a location in the scale of temperature configuring the domain. In order to do so, we have taken the normal temperature of the human body $-36^{\circ}-37^{\circ}-$ as landmark whereby hot would occupy one of the highest positions after concepts such as warm, lukewarm, or tepid (the lowest positions being occupied by such concepts as cool, or cold to list just a few).

\section{Hot}

\section{Warm}

Lukewarm

\section{Tepid}

$36^{\circ}-37^{0}$

\section{Cool}

\section{Cold}

\section{Gelid}

Fig.1 
Basic domains like temperature are, at the same time, determined by a range of preconceptual structures which stem from our interaction with the physical environment. These, pointed out by Johnson (1987) and referred to as image-schemas, share with Langacker's concept of basic domains their basic condition, and are bodily-grounded structures or concepts that enable the further structuring of our understanding of the world (such as the CONTAINER schema, the PATH schema, or the LINK schema).

Among those image schemas relevant for the configuration of the basic domain of temperature we find the SCALE schema and the EQUILIBRIUM schema, both of which account for the organisation of the basic domain of temperature and the focalisation of hot within it, as well as for the range of inferences subsequent to the concept.

Thus, as we have already noted above, hot stems from the sensory capacity of touch, and is focalised upon a scale where the landmark -or point of equilibrium- is provided by the temperature of the human body under normal circumstances, hot being focalised on the upper locations in the scale. Also, taking for granted $36^{\circ}-37^{\circ}$ as the normal temperature and considering the role of the EQUILIBRIUM schema, any factor -external or internal- threatening that temperature implies a loss of equilibrium, providing thus a number of inferences towards the positive or negative value we attribute to hot. In this view, when the external circumstances (e.g. cold weather) threaten our corporal temperature we seek hot things/places and regard them in a positive light (there is also what is known as temperature therapy which consists of applying hot packs or hot-water bottles to soothe pain). On the contrary, when there is no external agent threatening our well-being, heat becomes a threat in itself: we cannot touch or hold hot things - unless trained for it- for more than a few seconds without running the risk of being seriously burnt, we cannot swallow hot drinks or food, and we can hardly endure hot weather (which can also be the source of a number of illnesses). Moreover, a hot body temperature is also the first sign that there is something wrong in our body system, as well as the source of discomfort.

This two-fold quality of the concept hot is learnt at a very early stage in our lives and, thus, we seek hot things/places under certain conditions but also avoid them under others, or fight hot temperature itself -fever- with every possible means.

The concept hot as it has been outlined above appears in a number of expressions which derive their meaning from the rich set of inferences drawn from the basic domain of temperature (both in its positive and negative sides). Thus, a hot climate is a nice thing when you endure harsh, cold winters and usually evokes the concept of sunny holidays, summer, and holiday resorts (usually seaside). E.g. 8 :

8. The following examples are taken from the British National Corpus. http:// info.ox.ac.uk/bnc. We have kept the tagging as it appears in the corpus. 
(1) $\underline{\text { ADL }} 958$ It was midsummer and hot.

(2) CDY 34 He never noticed the brilliant sunny days, hot as the Mediterranean ...

(3) JYD 3838 The turquoise sea lapped softly at the hot white sands.

Yet, too much heat is also unpleasant and we tend to avoid it for we know that we have a limited capacity to deal with heat, and surpassing it is usually followed by harmful consequences:

(4) EDK 299 The epidemics of the hot, dry summers of 1890 s probably obscured ...

(5) KP5 1507 That rice was too hot when I had it (so I burnt my tongue).

(6) FSB 168 It became too hot for animals to live.

The dangerous, negative effects of heat are also present in the following idioms with hot, all of which make sense from the basic domain of temperature and our own physical experience:

\section{to be in hot water}

(7) CAE 1369 SPIKE LEE is once again in hot water, once again at a time when he's got a movie to promote.

(8) CH6 8823 DUCHESS IN DISGRACE: Fergie cools off on the holiday that landed her in hot water.

\section{a hot spot}

(9) K61 301 Well I, I think after this er people haven't appreciated yet that they've ... the grounds have become a bit safer than they were the hooligan element seemed to be taking over, they have er closed circuit television now, at Walsall, so they can get to the hot spot of any trouble ...

(10) KD0 12567 What is a hot spot is not a good spot.

\section{to make it hot for someone}

(11) B1X 2883 'Make it so hot for them here they'll have to leave!'

(12) HA5 1445 'When things got too hot for her at home with Margaret she'd often spend a night at my flat cooling off.'

\section{something too hot to handle}

(13) CEP 10598 Wilkinson's words are a clear warning to United that they have an explosive individual on their hands -and recent history confirms the view that Cantona may just be too hot to handle.

(14) H9D 412 Not too hot to handle for an old-fashioned family publisher like Jackson's? 


\section{a hot pursuit}

(15) G0L 974 A pack leader saw the police in hot pursuit, called six Sturmabteilungen to him, and led them into the stadium.

All the examples above are physically grounded and their negative sense comes directly from the basic domain of temperature: a rise of temperature implies a loss of equilibrium/balance which ultimately results in danger for human beings. We cannot stand too hot liquids, places, or things and, therefore, we regard them as dangerous and tend to avoid them (as in the case of hot water, or hot spot) or get rid of them as soon as possible (idea present in too hot to handle). The case of hot pursuit is a combination of danger and real consequences of pursuing somebody, that is physical exercise: the direct physical consequence of exercise is an increase of body temperature and sweating.

The dangerous consequences deriving from hot also give rise to a number of metonymic mappings providing the source for a metaphorical extension of hot. Thus, the danger resulting from hot things is metonymically mapped onto the target world of politics and finance yielding idioms such as hot potato (referring to a dangerous issue), or hot money (where danger results from the illegal source of that money):

\section{a hot potato}

(16) A2M 65 The case became a hot potato for the Government when Mr Yang was offered political asylum by Taiwan, China's old foe.

(17) K5M 3021 The biggest political hot potato is the decision to put VAT on domestic fuel bills

\section{hot money/profits}

(18) A1Y 183 He said: 'Look at the problems 12 years of Tory mismanagement will bequeath to us: a balance of payments deficit financed by hot money, casinotype operation - money which will fly away at the prospect of a Labour victory.

On the other hand, this purely physical domain of temperature grounding hot also provides the main source for a series of metaphorical mappings upon several much more elaborated target domains. Furthermore, the basic domain heavily accounts for the nonarbitrariness of the new concepts resulting from the mapping (a fact which, as we have already pointed out, runs against the view of the arbitrary nature of polysemous words implicit in classical semantics). The two target domains relevant for the purpose of this paper $^{10}$ where

9. The frequent expression hot on the heels (meaning 'immediately after') is an extension of this one.

10. Hot is also used to convey the taste of certain substances and spices in the mouth producing a burning sensation. Yet, we will not deal with all the senses for hot in the present paper basically for length's sake, and will concentrate exclusively on those present in Wilder's film and encapsulated in the title. 
temperature has been metaphorically mapped are those of sex and life. We will consider them in that order.

\section{SEX AND HEAT}

Lakoff (1987: 380-415) deals with the conceptualisation of certain emotions and feelings such as danger or anger in terms of metaphors and metonymies dealing with the temperature domain. Likewise, the source domain of temperature can also be mapped onto the target domain of sex. Thus, as occurs with anger, one of the physiological effects of sexual activity -including the first stages of the activity, such as attraction- is increased body heat. The combination of this body reaction with the general metonymic principle 'the physiological effects of an emotion stand for the emotion' yields a number of metonymies and metaphors for sexual activity and attraction which, according to Lakoff (1987: 410), account for expressions like "She's an old flame", "I'm burning with desire", or "She's got hot pants for you". In Lakoff's account, these expressions stem from a combination of two ontological metaphors THE BODY IS A CONTAINER FOR EMOTIONS and LUST IS HEAT.

In a similar manner, we have considered two main processes accounting for the vast range of idioms dealing with sex: on the one hand, the metonymy 'effect for emotion' when combined with the ontological metaphor THE BODY IS A CONTAINER FOR EMOTIONS yields expressions like

\section{To have (got) the hots for somebody}

(19) HGT 4695 But my, what a great body -no wonder Luke's got the hots for you.

The second big group of idioms dealing with sex in terms of body heat reflect the metaphors LUST IS HEAT and its twin PASSIONATE IS HOT, whose ultimate source is also a metonymic mapping: the cognitive process at work here is again the general metonymy 'effect for emotion': the only effect of sexual attraction/activity highlighted being that of changes in body temperature at the expense of other possible effects, and mapped onto the target domain of $\operatorname{sex}^{11}$. Thus, we have examples like:

\section{to be hot for somebody}

(20) FPS 180 Geoffrey was so hot for her you could have boiled an egg in his Y fronts.

\section{A hot affair}

(21) J0S 3336 Caroline told Fiona that she was having a hot affair with somebody at the office.

11. The discussion on types of metaphor and metonymy and the ways they interact falls out of the present paper. For more information see Croft (1993), Barcelona (1997), or Ruiz de Mendoza (1997). 


\section{Hot stuff}

(22) GVT 481 But at least you usually saw some hot stuff in foreign films, to make up for it -tarts in bed with blokes and that sort of thing.

Miscellany of expressions where hot is always related to sex:

(23) ED9 2331 Hot pictures

(24) ADR 1342 There are some steamy bed scene, which may be too hot for most of Kylie's young fans to see.

(25) BP4 708 As one of Rodin's most celebrated works, The Kiss did not find favour with public opinion in the USA in the 1880s, which decided that the nude marble sculpture was far too hot for public viewing.

(26) CDG 2105 He video-taped all the hot action, including some lesbian lovemaking.

(27) JYA 732 Shelley felt herself growing hot as he approached.

\section{LIFE AS HEAT}

A second set of idioms derives from the combination of the orientational metaphor MORE IS UP and the metonymic process whereby we refer to life by focusing on hot temperature. This process has a strong experiential grounding: we know that hot conditions are essential in the creation of new life -heat makes plants grow, and, similarly, pregnant women experience an increase of body temperature- and death always results in a dramatic loss of body heat ending in rigor mortis. Hence, by combining this metonymy and the metaphor MORE IS UP hot is used to refer to current, fresh, lively, or popular things/people, and expressions such as hot up or things started getting hot mean that some thing or event becomes more intense or exciting (sometimes showing a mixture of the danger and sex senses seen above) or that somebody grows more and more interested in something/somebody (not necessarily with sexual implications):

(28) BMG 1605 As the years passed, the exotic Eastern cats became the hot favourites.

(29) CEN 7525 New clothes are hot stuff.

(30) K59 2003 Hot stuff: Dr. John Watson with the laser which he believes could revolutionise welding work in the North Sea.

(31) B3K 1357 The music melody continues with Hot Stuff, an outrageous new musical which celebrates the era of 70's glam-rock.

(32) B3K 1437 HOT STUFF tells the story of ballroom dancing wimp Joe Soap who sells his soul to the devil in order to become the biggest rock star the world has ever seen. 
(33) KS8 802 Her follow-up 'Hot Stuff', one of the last year's best-selling CD albums, is a giant step forward, with a mixture of Latin rock and jazz with many different colours (and featuring saxophonist Andy Sheppard).

So far then we have seen some of the expressions in the lexical network around the concept hot (for complete chart see figure 2). Their implications with regard to the title which has originated the present study will be considered in the next section.

\section{The Relevance of 'HOT' IN SOME LiKe It Hot}

As we have briefly noted above, Billy Wilder's film pivots around a number of issues which share many things from the domains determining the network around hot or, rather, things susceptible of being hot. Thus, the Chicago of the late 1920s -which is the main local and temporal setting of the film's story- was a really 'hot place' due to the quasi-permanent state of war among the different gangs aiming at the total control of the business of alcohol, business which was the main source for enormous profits made up of basically 'hot money' that had necessarily to be laundered somewhere else. The second source of profit were the numerous clubs or speakeasies which provided alcoholic drinks, girls, and jazz music (jazz being considered 'hot music' par excellence) in a more or less disguised manner and were the object of continuous police raids (in such a way that they were also truly 'hot spots').

The 'hot money/profits' resulting from all these illegal business were usually laundered in the sunny -and, obviously, hot- Florida, a favourite place for Mafia meetings and also for middle-aged wealthy people avoiding the snow and cold of winter. As a result, Florida was also the target of many a girl looking for a 'hot -and profitableaffair' with somebody rich.

Furthermore, the trio starring in Wilder's film are also examples of 'hot behaviour': two men dressed like women were -and still are- regarded as something dangerous and full of sexual implications, and Marilyn Monroe has become an unquestionable symbol of what being 'real hot' or 'hot stuff' means (no wonder Tony Curtis had got the hots for her).

Finally, the male protagonists will be the object of a 'hot pursuit' both in Chicago and in the Florida hotel, the latter becoming thus a really 'hot spot' after the arrival of the Chicago gang.

Taking all these things into account, it is easy to see how the word hot in Some Like It Hot refers the audience directly to a complex semantic network most of which is reflected thematically in Wilder's film and puns back in the title. In this sense, the notion of relevance is not only fully compatible with a cognitive -encyclopaedic-description 
of the title under analysis, but also cannot be understood apart from it. Thus, the use of an implicature working upon the polysemous quality of hot and the lack of a concrete referent for it proves to be a highly communicative device which takes advantage of precisely that which could otherwise be the source of miscommunication: Wilder's title does not aim at activating a concrete domain but, rather, a whole array of possibilities and senses coming from different domains (nevertheless motivated by the basic domain providing the central sense of hot as a degree of temperature) which play a key role in the film and converge in the word hot. In this sense, we can say that the title is a good example of the Principle of Relevance at its best, that is, it manages to create the greatest contextual effect for a minimum processing effort and in a minimum space. Furthermore, relevance is ensured by the way our mental lexicon is organised, and by those cognitive processes that organise our thought in the holistic, encyclopaedic manner briefly described above. It is this encyclopaedic quality of our knowledge and lexicon that ensures the understanding of a title like the one which has originated this paper. This understanding is then further confirmed, as it could not be otherwise, by the full context provided by the film but, nevertheless, has already been triggered by our basic knowledge of how it feels when something is hot.

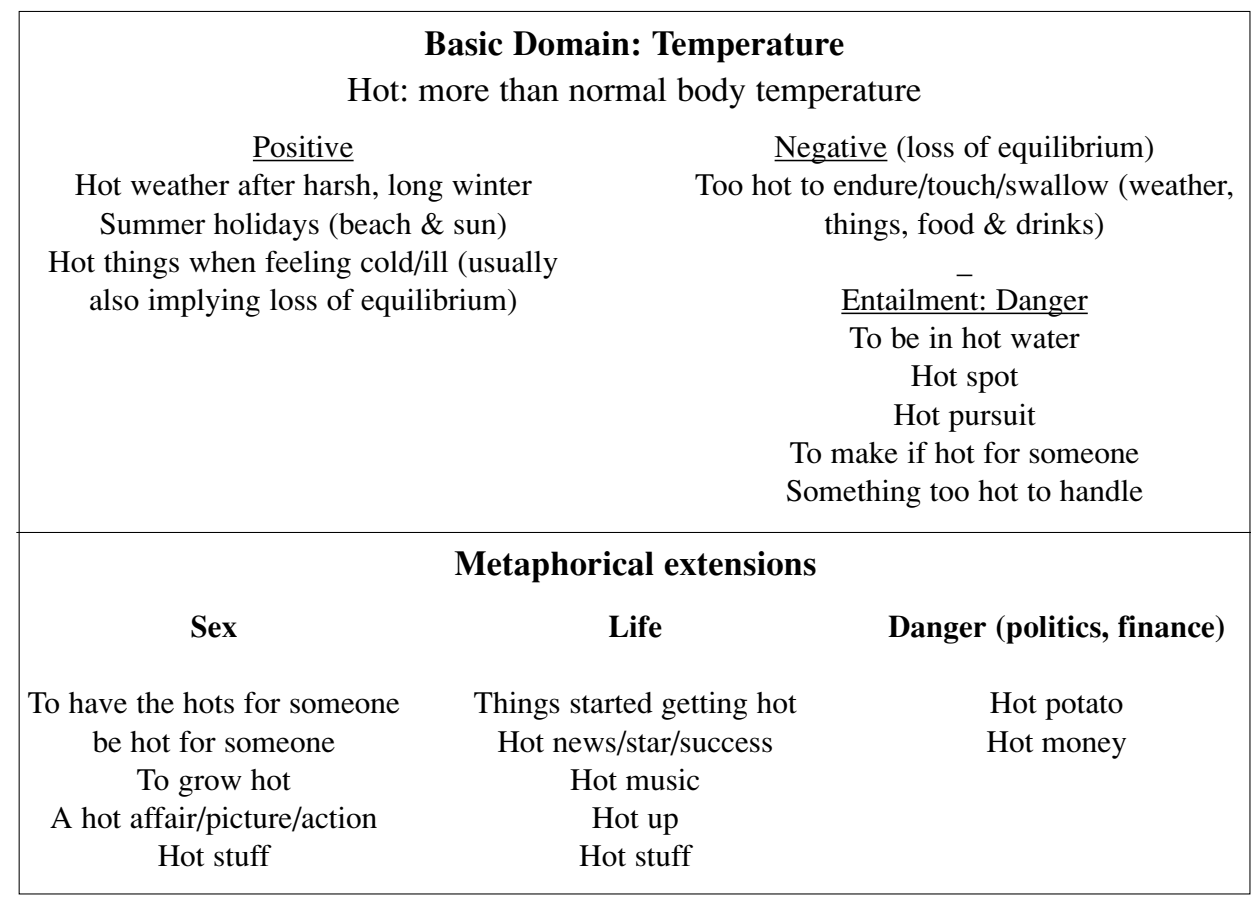

Fig. 2 


\section{REFERENCES}

Barcelona Sánchez, A. 1997. "Clarifying and applying the notions of metaphor and metonymy within Cognitive Linguistics". Atlantis 19, 1: 21-48.

Bartlett, F.C. 1932. Remembering. Cambridge: Cambridge University Press.

Croft, W. 1993. "The role of domains in the interpretation of metaphors and metonymies". Cognitive Linguistics 4-4: 335-371.

Downing, A. \& Locke, P. 1992. A University Course in English Grammar. New York: Prentice Hall.

García, F.J., F.J. Ruiz de Mendoza, and J.L. Otal 1994-95. "Hyperlexis: A hypertext system for representing lexical information at discourse level". Revista Española de Lingüística Aplicada: 101-119.

Gibbs, R.W. Jr. 1994. The Poetics of Mind: Figurative Thought, Language, and Understanding. Cambridge \& New York: Cambridge University Press.

Grice, P. 1975. "Logic and conversation". Syntax and Semantics, Vol. 9: Pragmatics. Eds. P. Cole and J. Morgan. New York: Academic Press. 41-58.

Johnson, M. 1987. The Body in the Mind. Chicago \& London: The University of Chicago Press.

Lakoff, G. 1987. Women, Fire, and Dangerous Things: What Categories Reveal about the Mind. Chicago \& London: The University of Chicago Press.

Lakoff, G. 1993 "The contemporary theory of metaphor". Metaphor and Thought, 2nd ed. Ed. A. Ortony. Cambridge \& New York: Cambridge University Press. 202-251.

Lakoff, G. and M. Johnson 1980. Metaphors We Live By. Chicago \& London: The University of Chicago Press.

Lakoff, G. and M. Turner 1989. More than Cool Reason: A Field Guide to Poetic Metaphor. Chicago \& London: The University of Chicago Press.

Langacker, R.W. 1987. Foundations of Cognitive Grammar: Theoretical Prerequisites. Stanford, CA: Stanford University Press.

Mandler, J.M. and N.S. Johnson 1977. "Remembrance of things parsed: story structure and recall". Cognitive Psychology 9: 111-151.

Minsky, M. 1975. "A framework for representing knowledge". The Psychology of Computer Vision. Ed. P. Evinston. New York: Mc Graw-Hill. 211-277.

Otal Campo, J.L. and F.J. Ruiz de Mendoza 1994. "Manifestabilidad mutua, estrategias de negociación y procedimientos discursivos", in Bruton, A., Sibón, T. \& Manchón, R. (eds.). Series sobre Estrategias de Aprendizaje y Uso del Lenguaje 2, CEP (Alcalá de Guadaira). 3-19.

Ruiz de Mendoza, F.J. and J.L. Otal Campo 1997. "Communication strategies and realization procedures". Atlantis 19, 1: 297-314. 
Ruiz de Mendoza, F.J. 1997. "Metaphor, metonymy, and conceptual interaction". Atlantis 19, 1: 281-295.

Rumelhart, D.E. 1980. "Schemata: The building blocks of cognition". Theoretical Issues in Reading Comprehension. Eds. R.J. Spiro, B.C. Bruce and W.F. Brewer. Hillsdale, N.J.: Erlbaum. 35-58.

Schank, R.C. and R. Abelson 1977. Plans, Scripts, Goals and Understanding. Hillsdale, N.J.: Erlbaum.

Winograd, T. 1975. "Frame representations and the declarative-procedural controversy". Eds. D.G. Bobrow and A.M. Collins. Representation and Understanding: Studies in Cognitive Science. New York: Academic Press. 185-210. 